\title{
Formation of the Apaf-1/cytochrome $c$ complex precedes activation of caspase-9 during seizure-induced neuronal death
}

\author{
DC Henshall ${ }^{\star, 1}$, DP Bonislawski ${ }^{1}$, SL Skradski ${ }^{1}$, T Araki $^{1}$, \\ J-Q Lan ${ }^{1}$, CK Schindler ${ }^{1}$, R Meller ${ }^{1}$ and RP Simon ${ }^{1}$ \\ 1 Robert S. Dow Neurobiology Laboratories, Legacy Research, Portland, OR \\ 97232, USA \\ * Corresponding author: DC Henshall, Robert S. Dow Neurobiology \\ Laboratories, Legacy Clinical Research \& Technology Center, 1225 NE 2nd \\ Avenue, Portland, OR 97232, USA. \\ Tel: (1) 503413 5260; Fax: (1) 5034135465 \\ E-mail: dhenshall@DowNeurobiology.org
}

Received 14.3.01; revised 26.4.01; accepted 24.5.01

Edited by G Nunez

\begin{abstract}
In this study we examine the in vivo formation of the Apaf-1/ cytochrome c complex and activation of caspase-9 following limbic seizures in the rat. Seizures were elicited by unilateral intraamygdala microinjection of kainic acid to induce death of CA3 neurons within the hippocampus of the rat. Apaf-1 was found to interact with cytochrome $c$ within the injured hippocampus $0-24 \mathrm{~h}$ following seizures by co-immunoprecipitation analysis and immunohistochemistry demonstrated Apaf-1/cytochrome $c$ co-localization. Cleavage of caspase-9 was detected $\sim 4 \mathrm{~h}$ following seizure cessation within ipsilateral hippocampus and was accompanied by increased cleavage of the substrate Leu-Glu-His-Asp-p-nitroanilide (LEHDpNA) and subsequent strong caspase-9 immunoreactivity within neurons exhibiting DNA fragmentation. Finally, intracerebral infusion of Z-LEHD-fluoromethyl ketone increased numbers of surviving CA3 neurons. These data suggest seizures induce formation of the Apaf-1/cytochrome $c$ complex prior to caspase- 9 activation and caspase- 9 may be a potential therapeutic target in the treatment of brain injury associated with seizures. Cell Death and Differentiation (2001) 8, $1169-1181$.
\end{abstract}

Keywords: bcl-2; apoptosis; programmed cell death; necrosis; mitochondria; brain; epilepsy; CED-4; kainic acid

Abbreviations: Apaf-1, apoptosis protease activating factor-1; CARD, caspase recruitment domain; LEHDpNA, N-acetyl-Leu-GluHis-Asp-p-nitroanilide; z-LEHD-fmk, z-Leu-Glu(OMe)-His-Asp(OMe)-fluoromethyl ketone; z-DEVD-fmk, Z- Asp-Glu(OMe)-ValAsp(OMe)-fluoromethyl ketone; VDVAD, Val-Asp-Val-Ala-Asp; $\mathrm{Ca}^{2+}$, calcium; KA, kainic acid; EEG, electroencephalogram; FITC, fluorescein isothiocyanate; TUNEL, terminal deoxynucleotidyl transferase (TdT)-mediated dUTP nick end labeling; TNF, tumor necrosis factor

\section{Introduction}

Cell death in neurological diseases may be under the control of the caspase family of cell death protease ${ }^{1-3}$ and while the initiating factor(s) remain to be clarified, surface-expressed, death receptor-linked caspase-8 or mitochondrion/cytochrome $c$-linked caspase- 9 are likely candidates. Caspase- 9 (Mch6/ICE-LAP6/Apaf-3) is an initiator of the intrinsic apoptotic cell death pathway and is an important activator of downstream effector proteases such as caspase-3. ${ }^{4,5}$ Caspase- 9 is localized within the cytoplasm of many cell types although is most likely tethered to the mitochondrion in neurons. ${ }^{6,7}$ Following apoptotic stimuli, caspase- 9 is released from the mitochondrion and is subsequently activated by oligomerization with apoptosis protease activating factor-1 (Apaf-1), the mammalian homolog of the $C$. elegans gene ced-4, ${ }^{8}$ released cytochrome $c$ and dATP/ATP. ${ }^{9-11}$ The Apaf-1/cytochrome $c$ complex interacts with procaspase- 9 via opposing homophilic CARDs (caspase recruitment domains) leading to autocatalytic processing and activation of caspase-

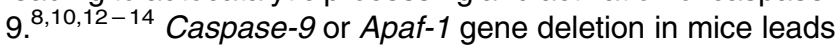
to death of the embryo in utero with animals exhibiting brain hyperplasia and other phenotypes arising due to defects in apoptosis. ${ }^{5,15}$ Interestingly, the phenotype of Apaf-1-deficient mice is more abnormal supporting the involvement of Apaf-1 in additional non-caspase-9 pathways. ${ }^{5,15-17}$

The mechanism by which seizures induce neuronal death remains incompletely understood and experimental studies have supported the involvement of both necrosis and apoptosis. ${ }^{18-21}$ Nevertheless, recent experimental and now human studies have implicated activation of caspases within vulnerable brain regions. ${ }^{22-27}$ While the events initiating the caspase cascade in these studies remain unknown caspase- 9 involvement is favored by longstanding observations on seizure-induced disruption of calcium $\left(\mathrm{Ca}^{2+}\right)$ homeostasis in mitochondria ${ }^{28,29}$ and the rapid release of cytochrome $c$ following seizures. ${ }^{25} \mathrm{We}$ therefore examined seizure-induced formation of the Apaf$1 /$ cytochrome $c$ complex in vivo and expression and processing of caspase- 9 following seizures. Presently, we demonstrate assembly of the Apaf-1/cytochrome $c$ complex occurs in vivo following seizures and this precedes caspase- 9 activation suggesting caspase- 9 is a candidate initiator of neuronal death following seizures.

\section{Results}

\section{Seizure model characteristics}

To examine the role of caspase- 9 in seizure-induced brain injury we elicited limbic seizures by intraamygdala microinjection of kainic acid (KA) as previously reported. ${ }^{25,30}$ 
Seizures were monitored throughout by three intracranial electrodes and were terminated after $40 \mathrm{~min}$ by intravenous diazepam resulting in unilateral death of $>50 \%$ hippocampal CA3 neurons with features of apoptosis. ${ }^{25,30}$ Neuronal death outside this region was minimal and confined to the injected amygdala and occasionally cortical neurons. While our EEG recordings suggest the seizures elicited by unilateral KA spread to the contralateral hemisphere as originally determined in this model, ${ }^{31}$ we did not detect significant DNA damage or neuronal death in this brain region in the present study despite previous reports of mild contralateral CA3 neuronal death in this model. ${ }^{30,32}$

\section{Apaf-1 localization in multiple cell compartments is unaffected by seizures}

Previous studies using our model demonstrated that seizures elicited by intraamygdala KA activate caspase- 3 within the ipsilateral CA3 subfield of the hippocampus and that this cell death is partly inhibited by z-DEVD-fmk, a caspase-3 inhibitor. ${ }^{25}$ Since seizures induce significant loss of intracellular calcium homeostasis ${ }^{33}$ and trigger cytochrome $c$ release ${ }^{25}$ we sought to examine the potential contribution of caspase- 9 as the initiator caspase in this system and its activating factor Apaf-1.

Constitutive Apaf-1 expression was detected in control rat brain (Figure $1 \mathrm{~A}$ ) and total protein levels were unaffected by seizures ( $n=3$ per group). To examine the subcellular distribution of Apaf-1 in rat brain we subjected seizure brain to subcellular fractionation to obtain cytosolic, nuclear and mitochondrial fractions. Figure 1B shows purity of each subcellular fraction. Subcellular fractionation ( $n=4$ per group) determined that Apaf-1 was constitutively present in nuclear, mitochondrial and cytosolic compartments examined (Figure $1 \mathrm{C}$ ) but seizures had no demonstrable effect on the subcellular expression levels of Apaf-1.

\section{Apaf-1 is expressed in neurons and co-localizes with cytochrome $c$ following seizures}

Apaf-1 activates caspase-9 following binding of cytochrome $c$, which is released from the mitochondrion in response to certain cell death/apoptotic stimuli. ${ }^{8,9} \mathrm{We}$ therefore used multi-label fluorescence immunohistochemistry to examine Apaf-1 expression and its localization with cytochrome $c$ following seizures. Constitutive Apaf-1 immunoreactivity was detected throughout the brain in control sections, mostly in cells that double-labeled for the neuronal marker NeuN (Figure $2 \mathrm{~A}-\mathrm{H}$ ). Apaf-1 also labeled cerebral microvessels throughout the cortex (Figure $2 \mathrm{C}$ ) but did not label cells within white matter tracts (not shown). High power microscopic examination determined Apaf-1 appeared most often as a diffuse but strong immunostaining pattern throughout cells (Figure 2l). However, in some cells Apaf-1 also exhibited punctate cytoplasmic labeling suggesting localization within intracellular compartments. Apaf-1 immunolabeling did not overlap with cytochrome $c$ to a significant extent in control neurons (Figure 2K). Twenty-four hours following seizures, Apaf-1 immunolabeling within many injured CA3 pyramidal
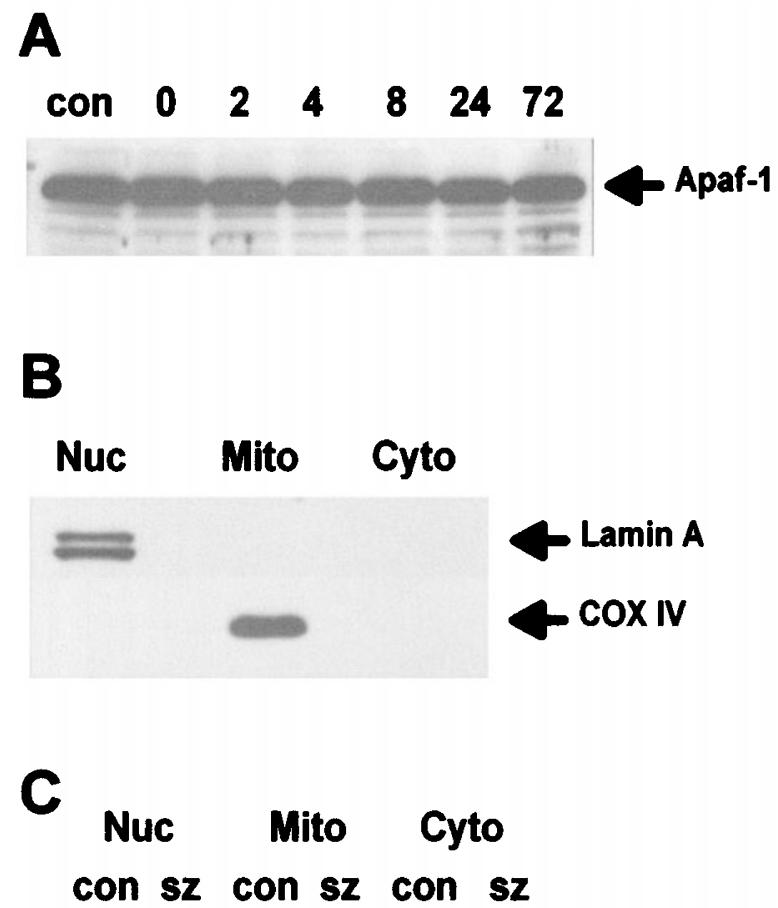

Figure 1 Apaf-1 expression following seizures. (A) Representative Western blot ( $n=1$ per lane) demonstrating strong constitutive expression of the $\sim 130 \mathrm{kDa}$ form of Apaf-1 in control (con) and seizure rat brain. Expression of Apaf-1 was unaffected by seizures. (B) Subcellular fraction purity is shown for the nucleus (nuc), mitochondria (mito) and cytoplasm (cyto). (C) Apaf-1 subcellular distribution in control brain samples and $24 \mathrm{~h}$ following seizures (sz) within nuclear, mitochondrial and cytosolic fractions. No difference in Apaf-1 distribution was detected following seizures. Time is shown in hours following seizure termination. COX IV, cytochrome IV oxidase

neurons became strongly punctate within the cytoplasm and overlapped with cytochrome $c$ (Figure $2 \mathrm{~L}-\mathrm{N})$. Quantification of this localization within the CA3 (from $n=4$ fields) determined that punctate cytosolic Apaf-1 immunolabeling markedly overlapped with cytochrome $c$ in more than $70 \%$ of neurons examined. Co-localization of Apaf-1 and cytochrome $c$ also became prominent in many cells of the piriform cortex and the amygdaloid nucleus, brain regions that often exhibit injury following seizures (not shown). These data support the largely neuronal expression of Apaf-1 and suggest Apaf-1 may associate with cytochrome $c$ during the cell death process initiated by seizures.

\section{Apaf-1 binds cytochrome $c$ in vivo following seizures}

To further establish the association of Apaf-1 with cytochrome $c$ following seizures we examined their in vivo interaction by immunoprecipitation using an antibody against cytochrome $c$ to extract associated proteins from ipsilateral (injured) hippocampal extracts ( $n=4$ per group). To confirm the 


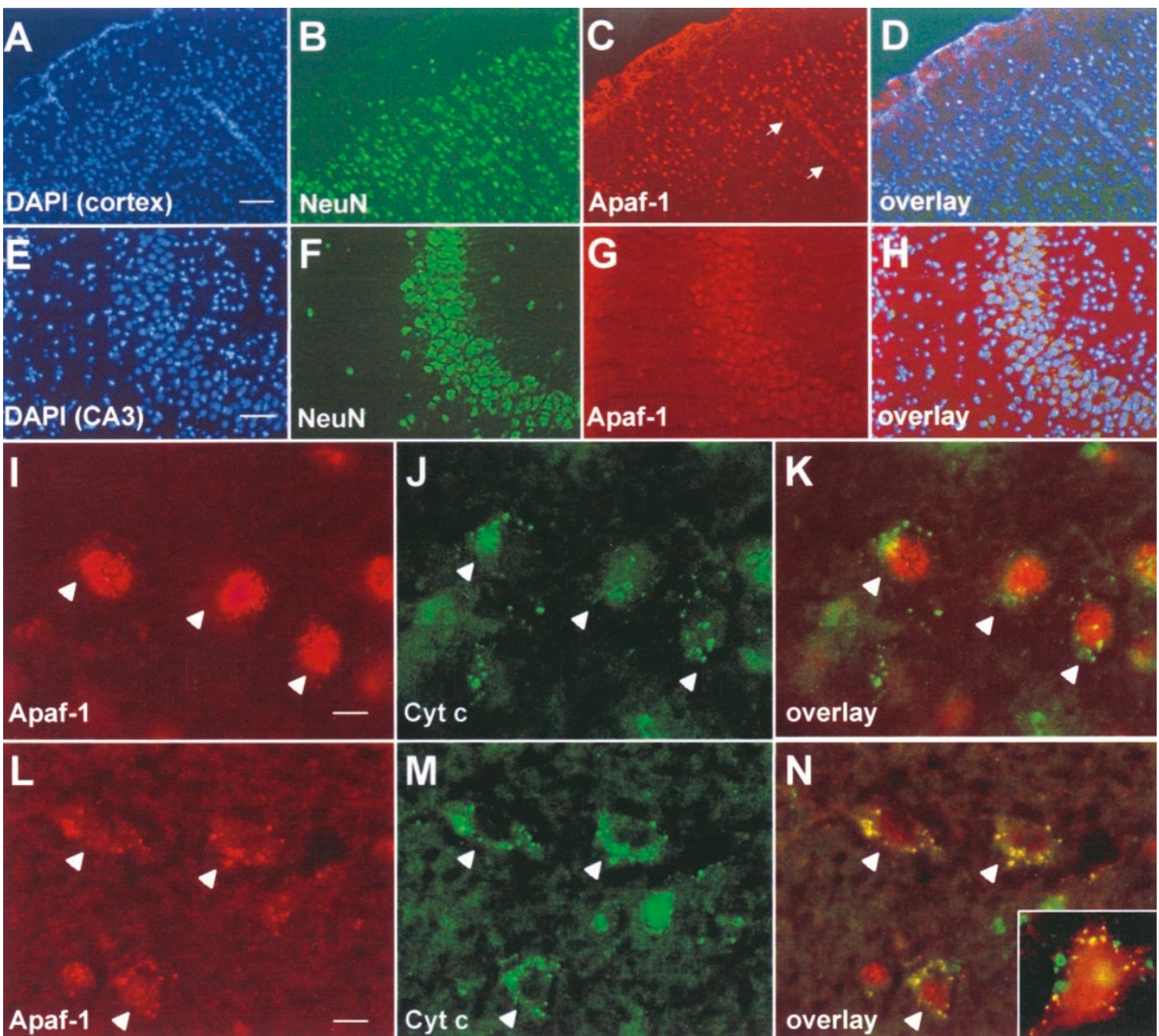

Figure 2 Apaf-1 immunohistochemistry and co-localization with cytochrome $c$ following seizures. (A-D) Immunohistochemistry determined that Apaf-1 (red) expression was mostly detected within NeuN-labeled (green) neurons in control rat brain cerebral cortex as confirmed by triple image overlay with the nuclear marker DAPI (blue). Apaf-1 was also expressed within cerebral microvessels (arrows in C). Apaf-1 was expressed within hippocampal CA3 neurons (G) as revealed by co-immunostaining with NeuN (F) and image overlay (H). High power microscopic analysis determined that Apaf-1 staining (I) had a diffuse cytoplasmic appearance. Cytochrome $c$ (green) labeling $(\mathbf{J})$ had a punctate, cytoplasmic appearance in control brain, and Apaf-1 and cytochrome $c$ did not co-localize $(\mathbf{K})$. Arrowheads mark particular cells of interest. Twenty-four hours following seizures, Apaf-1 immunoreactivity (L) exhibited a more punctate pattern of labeling within injured CA3 neurons which co-localized with cytochrome $c(\mathbf{M})$ as confirmed by yellow/gold coloring in image overlay $(\mathbf{N})$. Insert in (N) shows a 100X magnification of a single neuron within seizure-injured CA3. Yellow/gold puncta indicates extensive Apaf-1 (red) co-localization with cytochrome $c$ (green) following seizures Scale bar; $A-D=300 \mu \mathrm{m}, 5 \times$ magnification. $\mathrm{E}-\mathrm{H}=150 \mu \mathrm{m}, 10 \times$ magnification. $\mathrm{I}-\mathrm{N}=15 \mu \mathrm{m}, 40 \times$ magnification

specificity of the immunoprecipitation, whole brain lysate was probed with the Apaf-1 antibody (Figure 3A, lane 1), while a negative control (lane 2) shows the absence of any bands when the cytochrome $c$ antibody was omitted from the immunoprecipitation. Apaf-1 was not detected in control, non-seizure brain subject to immunoprecipitation with anticytochrome $c$ (Figure 3A, lane 3). In contrast, Apaf-1 was immunoprecipitated with cytochrome $c$ from samples extracted $0-24 \mathrm{~h}$ following seizures (Figure 3A, lanes 4-6). Cytochrome $c$ immunoprecipitation was confirmed by immunoblotting the same PVDF membranes with anti-cytochrome $c$ (Figure 3B). Positive (lane 1; whole cell lysate) and negative (lane 2; no immunoprecipitation antibody) controls confirm specificity. This result demonstrates that seizures trigger binding of constitutively expressed Apaf-1 to cytochrome $c$ providing in vivo evidence for the established model for Apaf-1/cytochrome $c$ complex formation during seizureinduced neuronal death in brain.

\section{Caspase-9 is activated following seizures}

Caspase-9 expression within neurons has previously been established and caspase- 9 is activated following a number of neurological insults. ${ }^{6,34}$ However, its role in seizureinduced brain injury remains to be demonstrated. We detected constitutive expression of the $\sim 50 \mathrm{kDa}$ form of procaspase-9 in rat brain within ipsilateral hippocampus (Figure 4A) and levels were relatively unaffected by 


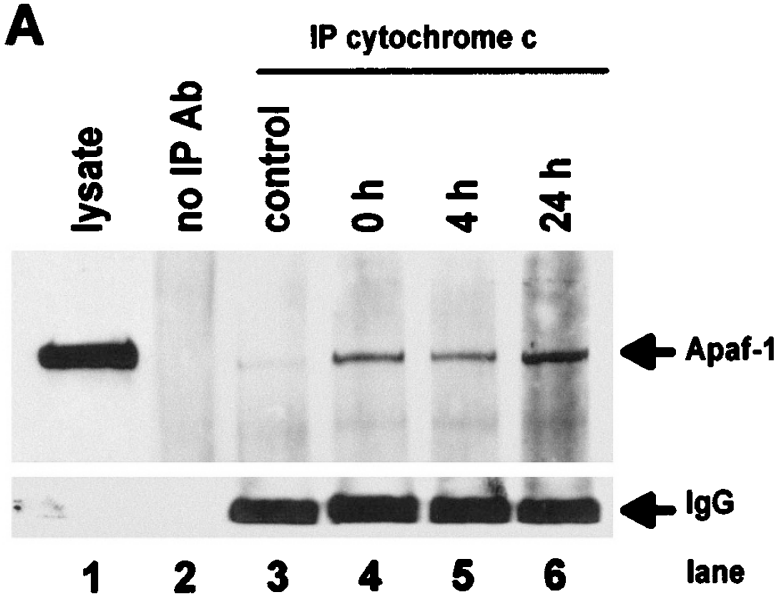

$\mathbf{B}$

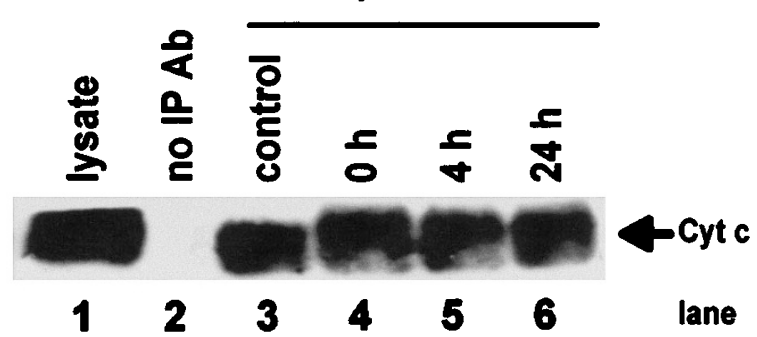

Figure 3 Immunoprecipitation of Apaf-1 with cytochrome $c$ following seizures. (A) Representative Western blot ( $n=2$ pooled samples per lane) showing total cell lysate detection of Apaf-1 (lane 1) as an $\sim 130 \mathrm{kDa}$ band. Lane 2, no cytochrome $c$ (IP) antibody (negative control). Lanes 3-6 show immunoprecipitation of control and seizure hippocampus using anticytochrome $c$ followed by probing with the Apaf-1 antibody. Lane 3, control (non-seizure) brain. Apaf-1 co-immunoprecipitated with cytochrome $c, 0 \mathrm{~h}$ (lane 4), 4h (lane 5) and 24h (lane 6) following seizures. Confirmation of immunoprecipitated cytochrome $c$ from total cell lysate is shown in $(\mathbf{B})$ for the same treatments. IP, immunoprecipitation; Ab, antibody; Cyt c, cytochrome $c$

seizures ( $n=3$ per group). Within ipsilateral hippocampus, a protein band of $\sim 17 \mathrm{kDa}$ corresponding to the large cleaved fragment of caspase-9 was detected $\sim 4 \mathrm{~h}$ following seizure termination, and very faintly at 0 and $2 \mathrm{~h}$, and this fragment persisted in samples until $72 \mathrm{~h}$ following seizures. In contrast, cleaved caspase- 9 was not detected within contralateral hippocampus (Figure 4B) or contralateral cortex but was detected in some samples within ipsilateral cortex (not shown). Additionally, in samples from seizure animals $(n=2)$ that received KA but did not undergo subsequent cell death-inducing polyspike paroxysmal discharges, also termed type IV seizures, ${ }^{27,30}$ the $17 \mathrm{kDa}$ band was either barely detectable or absent (not shown), supporting previous findings ${ }^{30}$ on the importance of this EEG pattern as the trigger for cell death.

To further establish caspase- 9 activation following seizures we assayed caspase-9-like protease activity based on the preferred cleavage substrate of caspase9. ${ }^{35}$ We detected significantly increased LEHDase activity within ipsilateral hippocampus at 4 and $8 \mathrm{~h}$ following

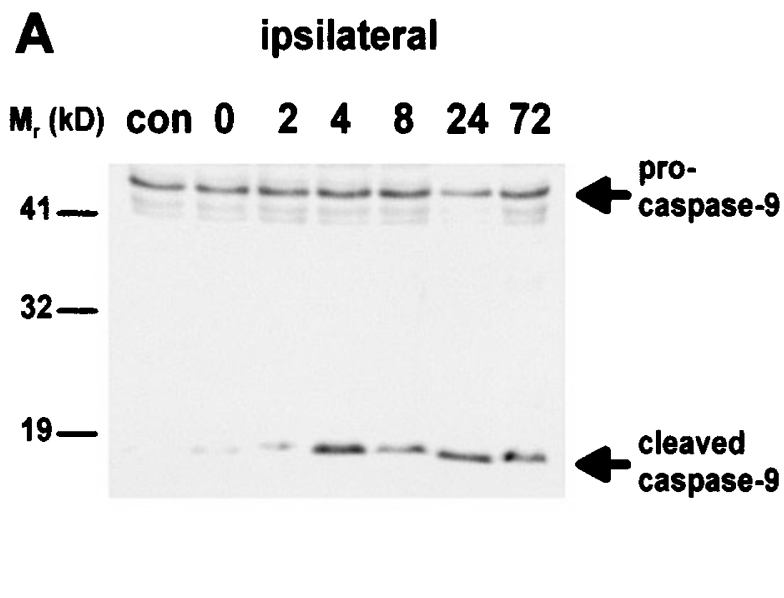

B contralateral

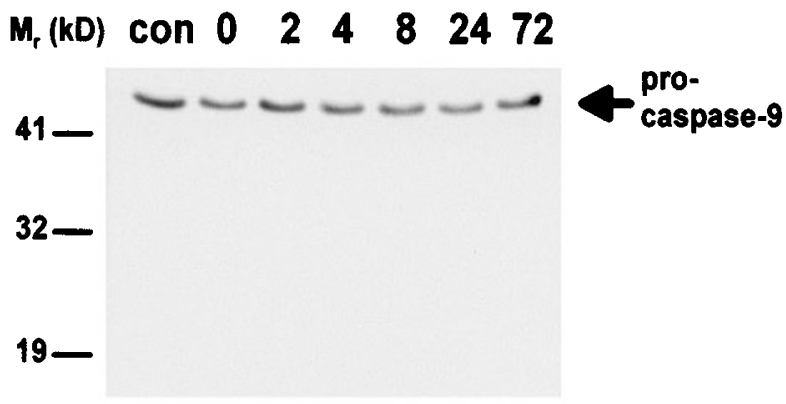

Figure 4 Caspase-9 expression and processing following seizures. (A) Representative Western blot showing constitutive expression of the $\sim 50 \mathrm{kDa}$ form of procaspase- 9 in control (con) and seizure rat brain ( $n=1$ per lane). Caspase- 9 cleavage as evidenced by the appearance of the cleaved fragment was detected $\sim 4 \mathrm{~h}$ following seizures and at all times thereafter. (B) Representative Western blot showing caspase-9 expression within contralateral hippocampus in which cleavage was not detected. Lane times are in hours following diazepam termination of seizures. Molecular weight $\left(M_{r}\right)$ standards are depicted to the left

seizures (Figure 5A) after which activity declined ( $n=4$ per group). Caspase- 9 activity also increased somewhat within ipsilateral cortex $8 \mathrm{~h}$ following seizures although this did not reach statistical significance (Figure 5B). No significant changes were detected within either contralateral brain region. These data therefore support previous studies examining caspase- 9 expression in brain and demonstrate that seizures activate caspase- 9 .

\section{Caspase-9 immunoreactivity is increased in TUNEL-labeled neurons following seizures}

To characterize the phenotype of caspase- 9 expressing cells and the association of caspase- 9 with the cell death mechanism we examined expression of caspase- 9 by fluorescence immunohistochemistry and its response during seizure-induced neuronal death. Caspase-9 immunoreactivity was constitutively present within rat brain, mainly in cells with the morphological appearance of neurons (Figure 6A-D). Immunolabeling was predominantly cytoplasmic and had a 
A

\section{Hippocampus}

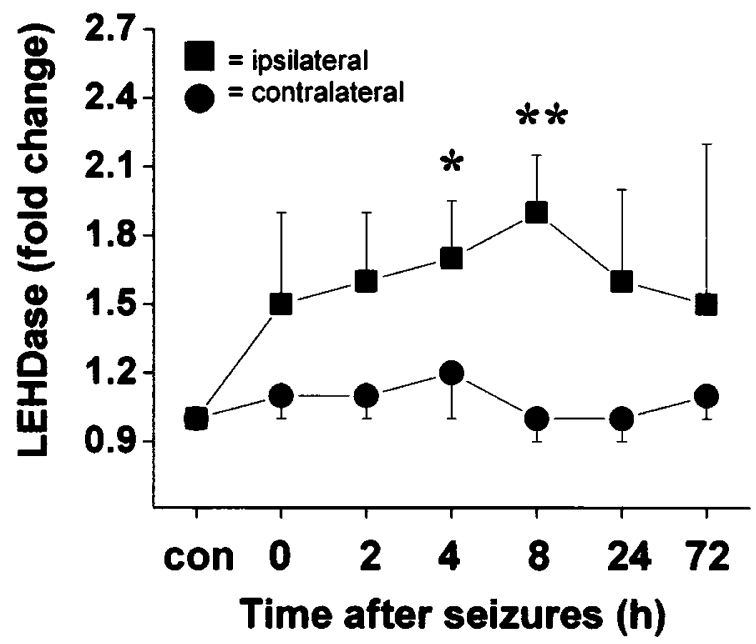

B

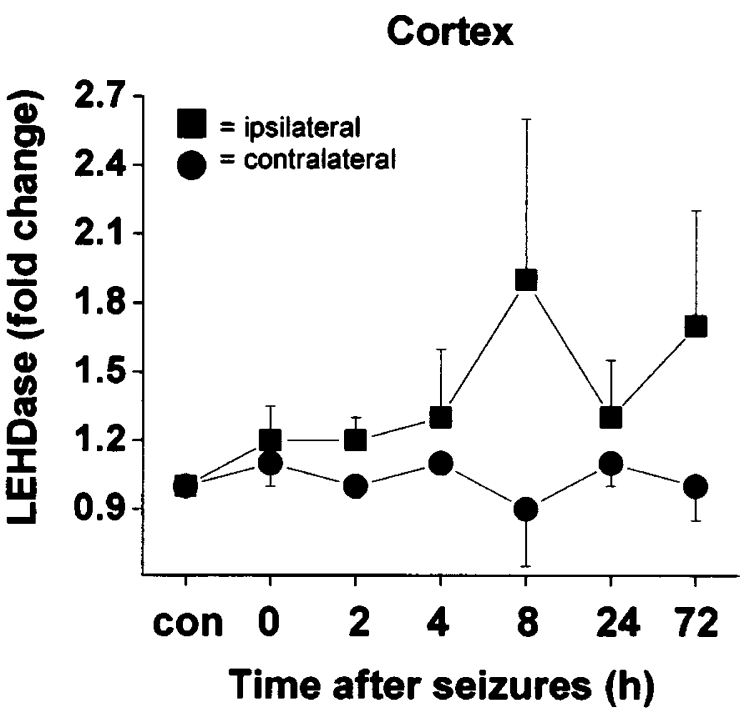

Figure 5 Increased caspase-9-like protease activity following seizures. Assay of caspase-9-like protease activity was performed based on the preferred LEHD amino acid substrate motif. (A) Seizures induced a significant increase in LEHDase activity within ipsilateral hippocampus $4 \mathrm{~h}$ and $8 \mathrm{~h}$ following diazepam compared to control (con). No significant changes in activity were detected in contralateral hippocampus. (B) Increases in LEHDase activity were also detected within ipsilateral cortex although this did not reach statistical significance. No changes in LEHDase activity were detected in contralateral cortex. Lane times are in hours (h) following diazepam termination of seizures. Data are shown as mean \pm S.E.M. ${ }^{*} P<0.05$. ${ }^{*} P<0.01$

somewhat punctate appearance in many cells. Caspase-9 was also detected in some cerebral microvessels at low level (Figure 6C) although this expression was not affected by seizures and caspase-9 immunoreactivity was not detected within white matter tracts (not shown). Twenty-four hours following seizures, caspase- 9 immunoreactivity was markedly increased within CA3 pyramidal neurons that co-labeled for the DNA fragmentation marker TUNEL (terminal deoxynucleotidyl transferase-mediated dUTP nick end labeling) (Figure 6E-H). Further, caspase-9 immunoreactivity appeared strongly nuclear in dying/TUNEL-positive CA3 neurons in addition to an extra-nuclear, punctate cytoplasmic distribution (Figure $6 \mathrm{G}$ and insert in $6 \mathrm{H}$ ). Thus caspase-9 is expressed mostly within neurons in brain and is strongly immunoreactive within the selectively vulnerable neurons that become TUNEL-positive following seizures providing additional circumstantial evidence for its role in mediating seizureinduced neuronal death.

\section{Intracerebral z-LEHD-fmk infusion reduces seizure-induced LEHDase activity in vivo}

To further examine the significance of caspase- 9 activation in seizure-induced neuronal death additional animals received intracerebroventricular (i.c.v.) infusions of the putatively selective caspase-9 inhibitor z-Leu-Glu(OMe)-His-Asp$(\mathrm{OMe})$-fluoromethyl ketone (z-LEHD-fmk) before seizures. Infusion of z-LEHD-fmk had no significant effect on the onset or offset time of seizures. Ex vivo assay of caspase-9-like protease activity ( $n=4$ per group) confirmed that seizures induced a significant increase in LEHDase activity $4 \mathrm{~h}$ following seizure termination in animals that received i.c.v. vehicle (Figure 7A). Administration of z-LEHD-fmk significantly reduced $(84 \pm 11 \%)$ LEHDase activity compared to vehicle-treated animals that underwent seizures (Figure 7A). Further, LEHDase activity in seizure animals infused with zLEHD-fmk was not significantly different to that found in nonseizure control animals supporting the effectiveness of zLEHD-fmk infusion using this dosing regime. Seizures also increased DEVDase activity ( $n=4$ per group), a putative measure of caspase-3/7 activity (Figure 7B) but while zLEHD-fmk reduced DEVDase activity by $19 \pm 45 \%$ ( $n=4$ per group) this change did not reach statistical significance. Seizures also induced a small ( $31 \pm 3 \% ; n=4$ per group) but significant $(P<0.0001)$ increase in VDVADase activity (Figure 7C), a putative measure of caspase-2-like activity. Interestingly, VDVADase activity was higher $(84 \pm 53 \%$ compared to non-seizure control group) in seizure animals that received zLEHD-fmk, although this increase did not reach statistical significance.

\section{Intracerebral z-LEHD-fmk infusion reduces seizure-induced DNA fragmentation and neuronal death}

Next we examined the in vivo effect of z-LEHD-fmk on TUNEL labeling and neuronal loss following seizures. Quantification of the EEG in these studies confirmed that the duration of all seizure types experienced by animals was equivalent between vehicle and z-LEHD-fmk-infused animals.

Seizures induced significant TUNEL labeling within cells of the CA3 subfield of the ipsilateral hippocampus when examined $72 \mathrm{~h}$ following diazepam administration (Figure $8 A$ ). Infusion of z-LEHD-fmk significantly reduced numbers of TUNEL labeled cells compared to seizure animals that received vehicle treatment $(n=6-7$ per group). No 

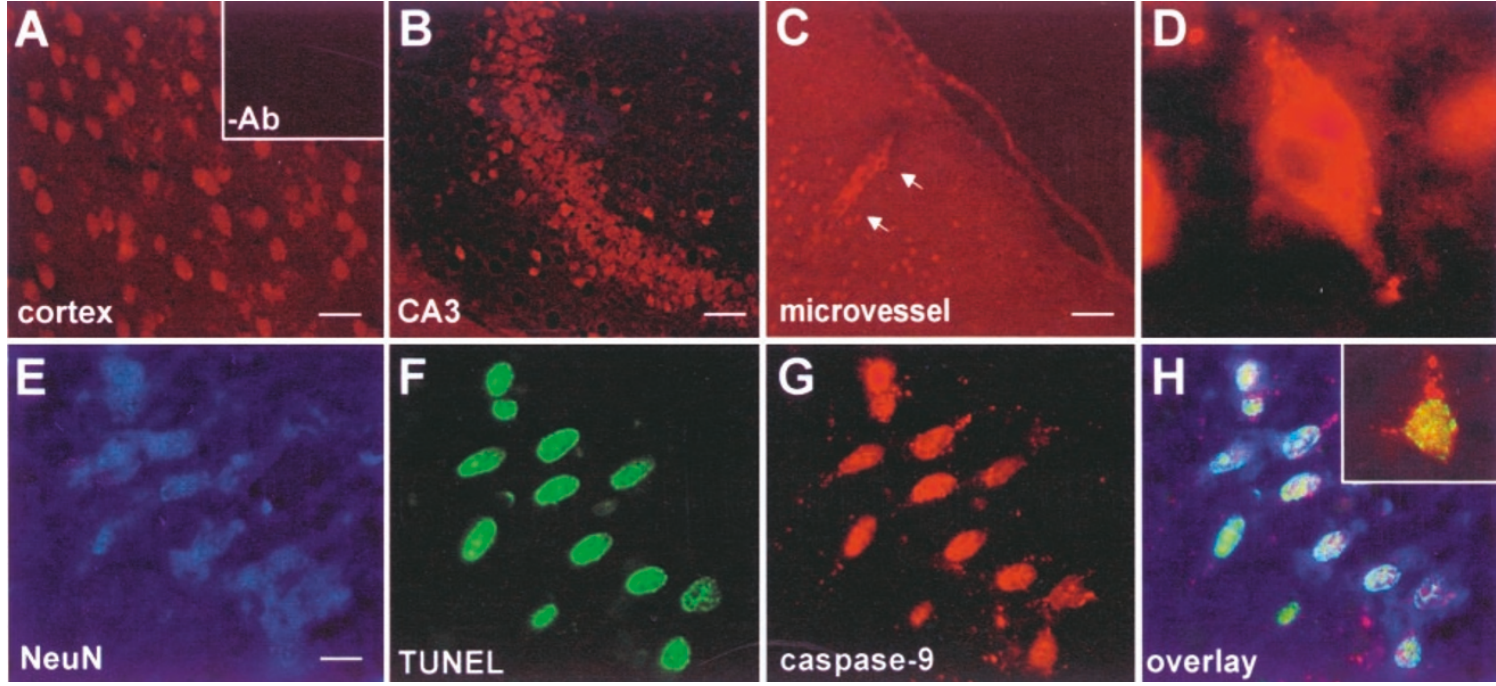

Figure 6 Caspase-9 immunohistochemistry and detection of TUNEL-positive cells following seizures. Caspase-9 immunolabeling (red) was constitutively present mostly in cells with the appearance of neurons within cortex (A) and hippocampus (B). Insert in $\mathbf{A}$ shows immunostaining of the cortex at $20 \times$ magnification from a section in which the caspase-9 antibody was omitted $(-A b)$. (C) Low power field showing caspase-9 immunolabeling of cells that include those of a cerebral microvessel (arrows). (D) A $100 \times$ magnification of a control caspase-9-labeled neuron. Note the largely cytosolic distribution with some red puncta suggestive of co-localization to intracellular structures. Twenty-four hours following seizures, (E) NeuN-labeled (blue) CA3 neurons that were TUNEL-positive (green) (F) exhibited increased caspase-9 immunoreactivity $(\mathbf{G})$ as revealed by image overlay $(\mathbf{H})$. Note strong nuclear appearance of caspase-9 immunoreactivity. Insert in (H) shows a $100 \times$ magnification of a single dying CA3 neuron $24 \mathrm{~h}$ following seizures. Caspase- 9 shows both nuclear overlap (yellow/gold center of cell) with TUNEL as well as an extra-nuclear (red puncta) localization, suggesting caspase- 9 is found in both compartments during the cell death process. Scale bar; $\mathrm{A}=50 \mu \mathrm{m}, 20 \times$ magnification. $\mathrm{B}=150 \mu \mathrm{m}, 10 \times$ magnification. $\mathrm{C}=300 \mu \mathrm{m}, 5 \times$ magnification. $\mathrm{E}-\mathrm{H}=30 \mu \mathrm{m}, 40 \times$ magnification

significant TUNEL labeling was detected within the contralateral hippocampus (Figure 8B). Quantification of seizure-induced loss of pyramidal neurons from the ipsilateral CA3 subfield by light microscope examination of cresyl violet stained sections demonstrated that in seizure animals which received i.c.v. vehicle there was a $51.9 \%$ (range $33-65 \%$ ) reduction in pyramidal neurons compared to numbers in non-seizure controls (Figure $8 \mathrm{C}$ ). In contrast, numbers of pyramidal neurons were significantly higher $(\sim 35 \%)$ in seizure animals that received $z$ LEHD-fmk.

Representative photomicrographs showing histological outcome following seizure-induced injury to the CA3 subfield with or without z-LEHD-fmk treatment are shown in Figures $9 A-F$. In addition, representative TUNEL labeling within the $\mathrm{CA} 3$ is shown for animals treated with or without z-LEHD-fmk (Figure 9G-I). These data suggest that z-LEHD-fmk confers significant protection on neurons within cell populations vulnerable to seizures.

\section{Discussion}

While the contribution of necrosis and apoptosis to seizureinduced neuronal death remains controversial ${ }^{20,21}$ there are experimental and now human data supporting the involvement of the caspase family of cell death regulatory proteases in this process. ${ }^{25-27}$ However, the molecular events responsible for initiation of the caspase cascade following seizures remain unknown. In this article we have demonstrated the constitutive neuronal expression of caspase- 9 and its activation co-factor Apaf-1 within rat brain. We found that
Apaf-1 and cytochrome $c$ interacted in vivo following seizures as determined by co-immunoprecipitation and immunohistochemistry and this preceded the appearance of cleaved and active caspase-9. Finally, we showed that a putatively selective caspase-9 inhibitor, z-LEHD-fmk, reduced seizureinduced cell death in vivo. These data demonstrate seizureinduced assembly of the Apaf-1/cytochrome $c$ complex occurs prior to caspase- 9 activation in vivo and may be an important initiator of neuronal death following seizures.

The caspase family of cell death proteases may control neuronal death and are potential treatment targets for a variety of neurological diseases including epilepsy. ${ }^{1,3,26}$ Initiation of cell death likely occurs either following activation of surface death receptors of the tumor necrosis factor (TNF) superfamily such as $\mathrm{Fas}^{36,37}$ or following release of apoptosis activating factors from the mitochondrion. ${ }^{38}$ Caspase- 9 is the principal caspase of the latter, intrinsic pathway that is activated following its oligomerization with Apaf-1 and released cytochrome $c^{9,10}$ and activation of caspase- 9 has now been demonstrated following neuronal injury in ischemia ${ }^{6}$ and Alzheimer's disease. ${ }^{34}$ However, little is known of the temporal sequence of this activation or the role of the principal activators of caspase- 9 following in vivo brain injury. The initial event in formation of the caspase- 9 activating complex is mitochondrial release of cytochrome $c,{ }^{9}$ an event reported following neurological injury in ischemia ${ }^{39,40}$ and after seizures. ${ }^{25}$ The precise mechanism responsible for release of cytochrome $c$ is much debated and likely model-specific, ${ }^{38}$ although stimuli include permeability transition pore formation, mitochondrial membrane insertion 
A

\section{Caspase-9-like activity}

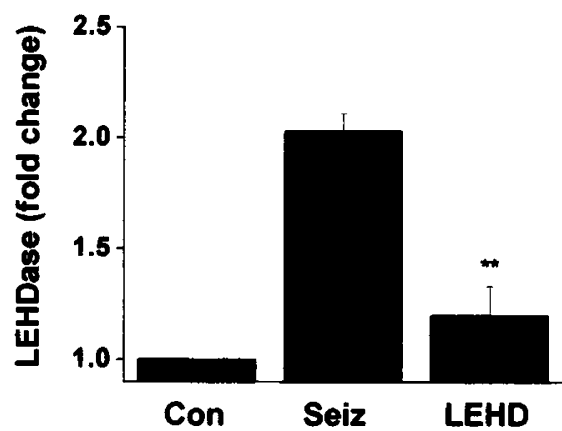

B

\section{Caspase-3-like activity}

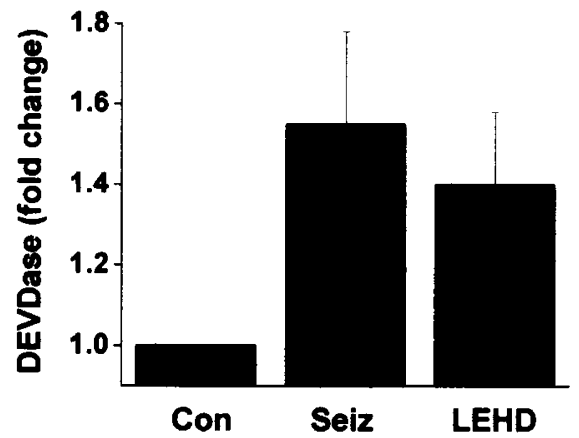

C

\section{Caspase-2-like activity}

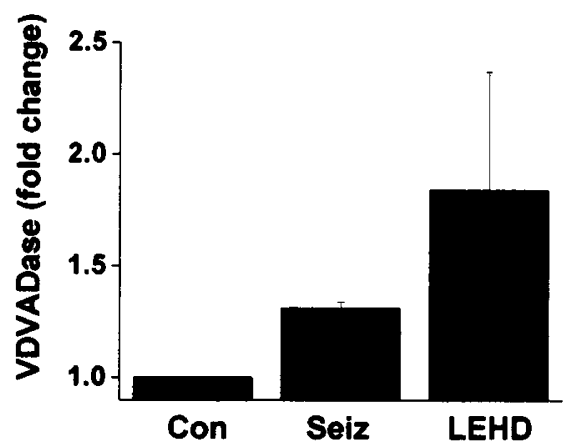

Figure 7 Effects of z-LEHD-fmk on caspase activity following seizures. (A) Measurement of caspase-9-like activity following seizures. z-LEHD-fmk significantly reduced LEHDase activity. (B) Measurement of caspase-3/7-like activity following seizures with or without z-LEHD-fmk. (C) Measurement of caspase-2-like activity following seizures with or without z-LEHD-fmk. Con, non-seizure control; Seiz, seizure control which received i.c.v. vehicle; LEHD, seizures+z-LEHD-fmk. ${ }^{\star \star} P<0.01$

of cleaved Bid and/or Bax and raised intracellular $\mathrm{Ca}^{2+} \cdot{ }^{41-43}$ While the trigger for seizure-induced cyto- chrome $c$ release has yet to be addressed, raised intracellular $\mathrm{Ca}^{2+}$ is a likely contributor since increased mitochondrial $\mathrm{Ca}^{2+}$ levels have long been established following seizures, ${ }^{33}$ probably as a result of prolonged and/or repeated glutamate receptor activation. ${ }^{44}$

Confirming previous studies, ${ }^{6,34,40}$ we detected constitutive neuronal expression of caspase- 9 and Apaf- 1 in brain (Figures 1, 2, 4 and 6). Control neuronal distribution of caspase- 9 had a somewhat punctate cytosolic appearance suggestive of co-localization to intracellular structures as previously reported. ${ }^{6}$ Following seizures, dying/TUNELpositive neurons exhibited strong nuclear expression of caspase-9 an observation reported following neuronal apoptosis after ischemia ${ }^{6}$ and suggestive of caspase- 9 translocation to the nucleus during cell death, an event reported for caspase-3. ${ }^{45}$ Also in agreement with previous studies $^{46}$ we found that Apaf- 1 had a largely diffuse somal distribution that did not suggest substantial sequestration to intracellular structures. Subcellular fractionation demonstrated that Apaf-1 resides largely within the cytosol but is also detected in the mitochondrial and nuclear compartments of the cell (Figure 1C) and seizures did not lead to re-compartmentalization of Apaf-1 consistent with reports by Zhivotovsky et al. ${ }^{7}$ and Hausmann et al. ${ }^{46}$ However, immunohistochemistry demonstrated that cellular distribution of Apaf-1 within seizure-damaged CA3 neurons did change, with Apaf-1 assuming a punctate appearance within cells and Apaf- 1 strongly co-localized with cytochrome $c$ (Figure 2N). This localization event is consistent with current models in which Apaf- 1 forms large complexes with cytochrome $c$ and caspase-9. ${ }^{11,47}$ However, this finding is in contrast to the report by Hausmann et al., ${ }^{46}$ in which apoptosis did not lead to demonstrable changes in the diffuse cytoplasmic distribution of Apaf-1. The explanation for the differences between these studies is unclear although may reside with differences between the cell death/apoptotic stimuli; in vitro UV radiation- and etoposideinduced apoptosis in considerable contrast to in vivo seizure-induced neuronal injury events in rat brain in the present report. However, our data complement to some extent findings for CED-4, the $C$. elegans gene product with which Apaf-1 shares homology, whereby CED-4 localized to intracellular (including nuclear) membranes during programmed cell death. ${ }^{48}$

To extend the immunohistochemical data on Apaf-1/ cytochrome $c$ association, their interaction in vivo was examined by immunoprecipitating cytochrome $c$ following seizures and immunoblotting with the antibody to Apaf- 1 . Formation of the Apaf-1/cytochrome $c$ complex has yet to be shown following brain injury in vivo. Here, we demonstrated that Apaf-1 rapidly forms a complex with cytochrome $c$ in the selectively vulnerable hippocampus following seizures (Figure $3 \mathrm{~A}$ ). This finding confirms and extends the immunohistochemical data and is contiguous with the established model of Apaf-1/cytochrome $c$ complex formation prior to caspase- 9 activation in vivo. The immediacy of this response also suggests Apaf- 1 may be amongst the first signaling elements to respond to seizureinduced cell injury, placing mitochondrial events at the apex of the death cascade following seizures. 
A

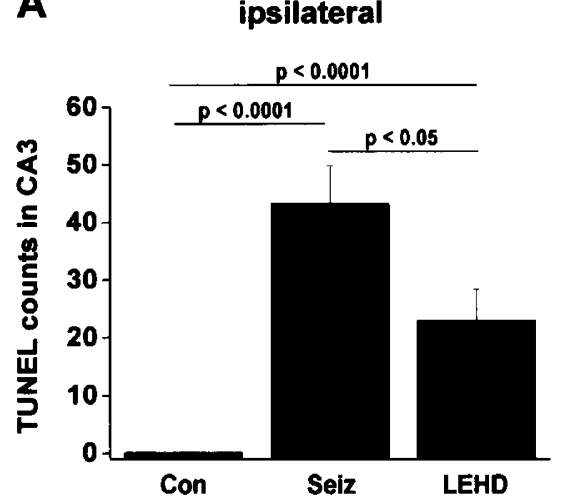

C

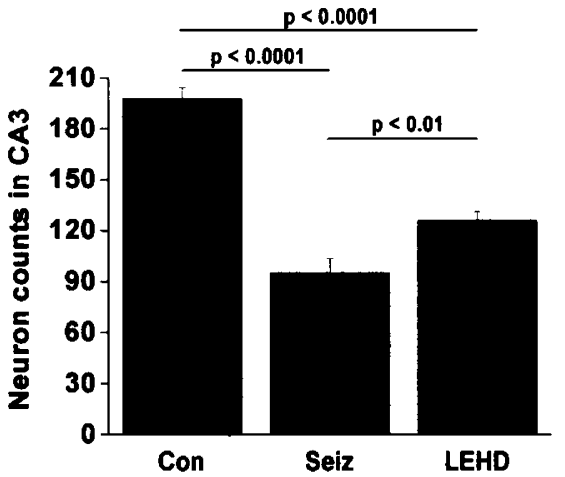

B

contralateral

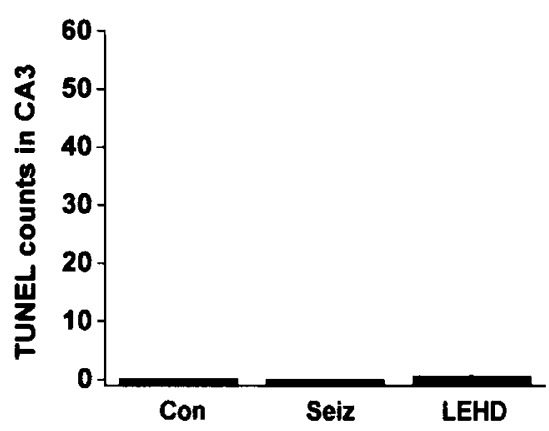

D contralateral

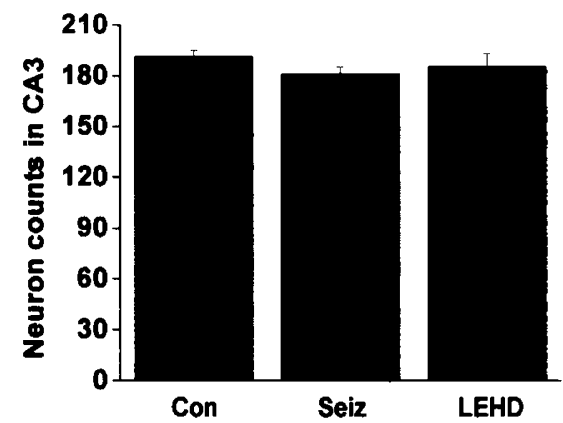

Figure 8 Effects of z-LEHD-fmk on seizure-induced DNA fragmentation and neuronal death $72 \mathrm{~h}$ following seizures for non-seizure controls, seizure controls and seizure animals which received z-LEHD-fmk. (A) TUNEL-positive cell counts within ipsilateral (injured) hippocampus showing z-LEHD-fmk significantly reduced TUNEL-positive counts within CA3 compared to seizure controls. (B) TUNEL cell counts within contralateral hippocampus. (C) Cell counts of surviving neurons from cresyl violet stained sections $72 \mathrm{~h}$ following seizures showing $\mathrm{z}$-LEHD-fmk significantly increased the number of surviving cells within the ipsilateral CA3 subfield of the hippocampus compared to seizure controls. No changes in numbers of neurons were detected in the contralateral CA3 subfield (D). Con, nonseizure control; Seiz, seizure controls which received i.c.v. vehicle; LEHD, seizure animals that received z-LEHD-fmk

Activation of caspase- 9 has been demonstrated in a number of neurological diseases including ischemia and Alzheimer's. ${ }^{6,34}$ We detected caspase-9 processing $\sim 4 \mathrm{~h}$ following seizures by Western blotting and increased LEHDase activity, the preferred substrate of caspase- 9 . $^{35}$ This temporal profile of activation is therefore consistent with a requirement for the upstream release of cytochrome $c$ and formation of the Apaf-1/cytochrome $c$ complex preceding caspase- 9 activation. Since caspase- 9 cleavage was detected $\sim 4 \mathrm{~h}$ following seizures and very faintly from $0-2 \mathrm{~h}$ (Figure 4A), this profile is also contiguous with an upstream role for caspase- 9 in the processing of caspase3 , the principal caspase target substrate of caspase-9, which is cleaved $4 \mathrm{~h}$ following seizures. ${ }^{25}$ Further, caspase9 cleavage largely precedes the morphological appearance of cell death in this model ${ }^{30}$ circumstantial support for its involvement as an initiator of cell death following seizures.

In further support of the involvement of caspase-9 in seizure-induced neuronal death we found that z-LEHD-fmk, a putatively selective caspase- 9 inhibitor reduced seizureinduced DNA fragmentation and cell death within the vulnerable CA3 subfield. This is the first study to demonstrate a neuroprotective effect of z-LEHD-fmk in the setting of seizure-induced neuronal injury. Further, if zLEHD-fmk were blocking exclusively at the level of caspase- 9 this may suggest intervention in the cell death process can be commenced after the point of cytochrome $c$ release but before induction of the final executioner phase of cell death involving caspases such as caspase-3. The question of whether the 'point-of-no-return' lies before or after cytochrome $c$ release remains undetermined ${ }^{49}$ and while these data fall well short of a satisfactory answer they nevertheless add to an emerging view that cells might recover following cytochrome $c$ release if caspases are blocked. An additional finding of interest was that z-LEHDfmk seemed to increase VDVADase activity perhaps reflecting previous observations of a function of caspase2 as a compensatory caspase following loss of caspase-9 in vivo. ${ }^{50}$ However, since the contribution of caspase-2 activation to seizure-induced neuronal death is questionable, ${ }^{27}$ any such compensatory response may have limited significance. 


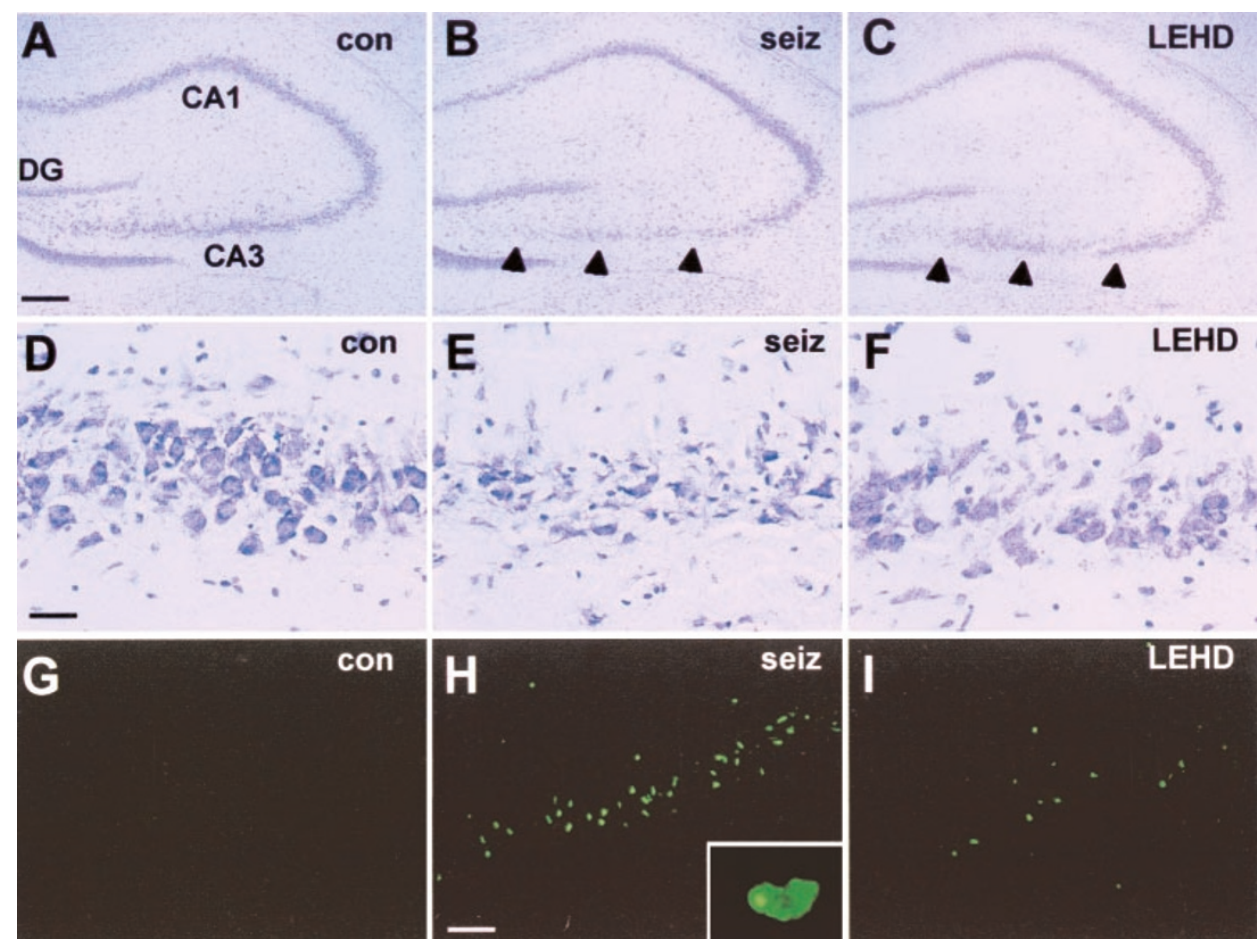

Figure 9 Histopathological micrographs illustrating effects of Z-LEHD-fmk on neuronal injury following seizures. (A) Low power $(2.5 \times)$ photomicrograph showing cresyl violet staining of the entire hippocampus of a non-seizure control animal. (B) Photomicrograph from a seizure animal illustrating $~ 50 \%$ loss of CA3 neurons $72 \mathrm{~h}$ following seizure termination. (C) Low power view of hippocampus from an animal subject to seizures that received z-LEHD-fmk. Note the partial sparing of neurons within CA3. Arrowheads denote region of interest. (D) High power $(20 \times)$ photomicrograph showing CA3 pyramidal neurons from a non-seizure control animal. (E) Same power field from a representative seizure animal demonstrating death of many CA3 neurons. (F) View of the CA3 field from a representative animal that underwent seizures but received z-LEHD-fmk. (G) Low power $(10 \times)$ field of TUNEL-positive labeling (green) within the hippocampus of a non-seizure control animal in which TUNEL-positive cells were not detected. $(\mathbf{H})$ TUNEL labeling within the CA3 from a seizure-animal demonstrating extensive labeling of many cells. Insert in (H) shows high power magnification of a representative TUNEL positive cell. Note the lobular shape suggestive of chromatin condensation in the nucleus. (I) TUNEL-labeling of cells within CA3 from a representative animal that received z-LEHD-fmk during seizures. Con, non-seizure control; Seiz, seizure controls which received i.c.v. vehicle; LEHD, seizures+z-LEHD-fmk. Scale bar; A-C=350 $\mu \mathrm{m}$. D-F=40 $\mu \mathrm{m}$. G-I is $100 \mu \mathrm{m}$. DG=dentate gyrus; CA1/ 3=hippocampal subfields

In the present studies z-LEHD-fmk did not confer greater protection on the brain than was previously demonstrated with z-DEVD-fmk in this model. ${ }^{25}$ This is surprising since blockade of the caspase cascade at a more proximal site might be predicted to exert a more pronounced protective effect. The explanation for this remains unknown but may be due to a ceiling effect in this model, particularly if a substantial aspect of seizure-induced cell death occurs independently of caspases. The application of more selective caspase inhibitors in the future combined with additional studies to determine the temporal and sequential ordering of other caspases may better define the likely contribution of those caspases involved.

A number of limitations must be considered when interpreting the findings of the present study. First, Apaf1/cytochrome $c$ complex formation may not be the exclusive activation mechanism for caspase- 9 as other co-factors and/or pathways have been proposed. ${ }^{51,52}$ Second, the LEHD cleavage motif is not ideally selective for caspase- 9 since this substrate preference is shared with caspases 4 and 5 and may be a suitable substrate for caspases 6 and $8 .^{35}$ Finally, other caspases must also be considered as candidate initiators of the caspase cascade including caspase- $8^{27}$ which can also process caspase-3 and is activated following stimulation of death receptors in a number of models of apoptosis ${ }^{36,37}$ and both caspase- 8 and death receptors of the TNF superfamily are expressed in brain. ${ }^{53,54}$ Further studies are required to fully elucidate the sequence of events in the initiation of the caspase cascade following seizures.

This study demonstrates seizure-induced caspase-9 activation. However, questions remain as to the significance of this event in the control and regulation of the cell death process following seizures. Despite evidence for neuronal apoptosis following seizures, ${ }^{18,25,55}$ many cells within affected populations also exhibit features consistent with necrosis. ${ }^{19-21}$ While many researchers favor caspase activation as an exclusively apoptotic process, ${ }^{56,57}$ the ultrastructural features of necrosis in some seizuredamaged neurons suggest activation of the caspase pathway may occur concurrently with non-apoptotic cell death. Seizure-induced neuronal death may therefore be analogous with recent classifications of caspase-dependent cell death with necrotic features. ${ }^{52,58}$ Additional studies may help to clarify the nature of seizure-induced neuronal death and the extent to which caspases control this process. 
The question of whether the present data translate into the clinical setting is unknown. There remains no clear consensus as to whether seizures, other than those during status epilepticus, ${ }^{59}$ trigger neuronal death ${ }^{60,61}$ or whether the relatively brief seizures in these studies would trigger comparable changes in humans. Neuroimaging studies support seizure-induced death of neurons within the hippocampus $^{62,63}$ and our previous studies have shown increased expression and cleavage of caspase- 3 in brain samples from patients that underwent temporal lobe resection for recurrent seizures. ${ }^{26}$ In that study, activation of caspase-3 was detectable in brain from patients experiencing as few as 1-2 seizures per day (unpublished data) and the majority of these patients were experiencing seizures originating from the temporal lobe, ${ }^{26}$ to which our model may be analogous, suggesting human correlates may well exist. The clinical data also confirmed correlates existed between seizure frequency and expression of $\mathrm{Bcl}-$ $\mathrm{x}_{\mathrm{L}}{ }^{26}$ a gene that (negatively) regulates the cell death pathway, further support that involvement of apoptosisregulatory proteins inferred by experimental observations do reflect clinically relevant phenomena. Undoubtedly further studies are required to substantiate links between findings in experiment seizure models and brain injury in human epilepsy patients, however these data do suggest incorporation of neuroprotective strategies targeting the caspase pathway may have clinical applications.

In summary, we have demonstrated that caspase-9 and the molecular machinery for its activation are present in brain. Further, Apaf-1 and cytochrome $c$ form a complex temporally upstream of caspase- 9 activation following seizures. These data support a role for caspase- 9 in seizure-induced neuronal death and suggest caspase-9 and/or components of its activation system may be potential targets to mitigate brain injury in epilepsy.

\section{Materials and Methods}

\section{Seizure model}

All animal procedures were performed in a facility accredited by the Association for Assessment and Accreditation of Laboratory Animal Care (AAALAC) International in accordance with protocols approved by the Legacy Institutional Animal Care and Use Committee and the principles outlined in the National Institute of Health Guide for the Care and Use of Laboratory Animals. Adult male Sprague-Dawley rats $(280-350 \mathrm{~g})$ underwent seizures induced by unilateral stereotaxic microinjection of kainic acid (KA) into the basolateral amygdala nucleus as previously described. ${ }^{30}$ Briefly, animals were anesthetized, intubated, ventilated and fitted with a venous catheter for drug administration. Animals were then placed in a stereotaxic frame and implanted with three recording electrodes (Plastics One, Inc, Roanoke, VA, USA) and an injection cannula. Anesthesia was discontinued, EEG recordings were commenced and then a 31 gauge internal cannula (Plastics One Inc.) was inserted into the lumen of the guide to inject $\mathrm{KA}(0.1 \mu \mathrm{g}$ in $0.5 \mu \mathrm{l}$ saline vehicle) into the amygdala. Nonseizure control animals underwent the same surgical procedure but received intraamygdala vehicle injection. The EEG was monitored until diazepam (30 mg/kg; intravenous) was administered to terminate seizures after $40 \mathrm{~min}$. The EEG was further monitored for up to $1 \mathrm{~h}$ to ensure seizure cessation. Quantification of the EEG into four (type IIV) principal patterns was performed blind to treatment as previously described $^{30}$ and no significant differences were detected between groups in the duration of each principal pattern of seizure activity (not shown).

\section{Western blotting}

Animals were euthanized $0,2,4,8,24$ or $72 \mathrm{~h}$ following administration of diazepam in seizure animals or after 4 or $24 \mathrm{~h}$ in non-seizure controls and ipsilateral and contralateral hippocampi and piriform cortex were obtained. Brain samples were homogenized and lysed in buffer containing the protease inhibitors phenylmethylsulfonylfluoride (PMSF) $100 \mu \mathrm{g} / \mathrm{ml}$, leupeptin $(1 \mu \mathrm{g} / \mathrm{ml})$, pepstatin $(1 \mu \mathrm{g} / \mathrm{ml})$ and aprotinin $(1 \mu \mathrm{g} / \mathrm{ml})$. Protein concentration was determined using Bradford reagent spectrophotometrically at $A^{595} \mathrm{~nm}$ and $50 \mu \mathrm{g}$ samples were denatured in gel-loading buffer at $100^{\circ} \mathrm{C}$ for $6 \mathrm{~min}$ and then separated on $12 \%$ SDS-polyacrylamide gels. Proteins were transferred to PVDF membranes (BioRad, Hercules, PA, USA) and then incubated with a rabbit polyclonal antibody against caspase- 9 (1:500 dilution), which recognizes the cleaved, large fragment (Cell Signaling Technology, Beverly, MA, USA) or a 1:1000 dilution of a rabbit polyclonal Apaf-1 antibody (Stressgen Biotechnologies, Victoria, British Columbia, Canada). Membranes were then incubated with a secondary antibody (1:2000 dilution) followed by chemiluminescence detection (NEN Life Science Products, Boston, MA, USA), and then exposed to Fuji RX film (Fuji, Tokyo, Japan). Images were collected with a Dage 72 camera and gel-scanning integrated optical density software (Bioquant, Nashville, TN, USA).

\section{Subcellular fractionation}

Ipsilateral hippocampus extracted $24 \mathrm{~h}$ following diazepam in control or seizure animals was processed to obtain cytosolic, mitochondrial and nuclear fractions according to previously described techniques ${ }^{7,25}$ with modifications. Briefly, tissue was homogenized in buffer containing $100 \mathrm{mM}$ sucrose, $1 \mathrm{mM}$ EGTA, $20 \mathrm{mM}$ MOPS, pH 7.4 with $5 \%$ Ficoll, $0.01 \%$ digitonin, $1 \mu \mathrm{g} / \mathrm{ml}$ aprotinin, $1 \mu \mathrm{g} / \mathrm{ml}$ pepstatin, $2 \mu \mathrm{g} / \mathrm{ml}$ leupeptin, and $100 \mu \mathrm{g} / \mathrm{ml} \mathrm{PMSF}$ and incubated for $15 \mathrm{~min}$ on ice. Samples were then centrifuged at $2500 \times g$ for $10 \mathrm{~min}$ to precipitate the nuclei and cellular debris. The supernatant was then centrifuged at $15000 \times g$ for $15 \mathrm{~min}$ to pellet mitochondria. The supernatant was subsequently centrifuged at $100000 \times g$ for $60 \mathrm{~min}$ to obtain the cytosol (supernatant). The pellet containing the nuclei was resuspended in $10 \mathrm{mM}$ Tris, $2.5 \mathrm{mM} \mathrm{KCl}$, and $2.5 \mathrm{mM} \mathrm{MgCl}_{2}$ and centrifuged through $2.1 \mathrm{M}$ sucrose at $90000 \times g$ to recover the nuclear fraction. Fractional purity was confirmed by immunoblotting with lamin $A$ for nucleus (Cell Signaling Technology) and cytochrome IV oxidase for mitochondria (Molecular Probes Inc, Eugene, OR, USA).

\section{Co-immunoprecipitation}

Animals were euthanized 0,4 or $24 \mathrm{~h}$ following administration of diazepam in seizure animals or after $4 \mathrm{~h}$ in non-seizure controls. Brain samples were homogenized and lysed in buffer containing 1\% NP-40 and the same protease inhibitor cocktail used for Western blotting and protein concentration was determined as described previously. Protein samples $(1 \mathrm{mg}$ ) were incubated with $5 \mu \mathrm{g}$ cytochrome $c$ antibody (Pharmingen, San Diego, CA, USA) overnight at $4^{\circ} \mathrm{C}$ and then incubated with protein $A / G$ agarose beads (Santa Cruz Biotechnology, 
Santa Cruz, CA, USA) for $2 \mathrm{~h}$ at $4^{\circ} \mathrm{C}$. The protein-bead complex was then washed, collected by centrifugation and samples were boiled in loading buffer and run on $12 \%$ SDS-PAGE gels, probed with anticytochrome $c$ (Pharmingen) and anti-Apaf-1 (Stressgen Biotechnologies) and processed as described for Western blotting. Controls included running $50 \mu \mathrm{g}$ whole cell lysate samples concurrently with the immunprecipitation samples to confirm antibody specificity and omitting the immunoprecipitating (cytochrome $c$ ) antibody.

\section{Caspase enzyme assay}

Assay of caspase-9-like protease activity was performed according to previously described techniques. ${ }^{25}$ Briefly, animals were perfused with $50 \mathrm{ml}$ ice-cold PBS to remove contaminating intravascular blood components. Whole protein was extracted from each brain region of interest in lysis buffer (R \& D Systems, Minneapolis, MN, USA) and $100 \mu \mathrm{g}$ samples were incubated with reaction buffer and $5 \mu \mathrm{l}$ of colorimetric caspase-9 substrate ( $\mathrm{N}$-acetyl-Leu-Glu-His-Asp-p-nitroanilide [Ac-LEHD-pNA]) in $105 \mu \mathrm{l}$ total volume for $90 \mathrm{~min}$ at $37^{\circ} \mathrm{C}$ according to manufacturer's recommendations ( $R$ \& $D$ Systems). Enzyme catalyzed release of $p$-NA was measured at $405 \mathrm{~nm}$ using a microtitre plate reader (Molecular Devices, Palo Alto, CA, USA). Activity was expressed as fold(s) change over control once corrected for baseline (protein and buffer without colorimetric substrate).

\section{Immunohistochemistry and DNA fragmentation}

Fresh frozen cryostat sections $(12 \mu \mathrm{m})$ from animals euthanized $0-$ $72 \mathrm{~h}$ following seizures ( $n=3$ per group) were pre-blocked in $2 \%$ goat serum and then incubated overnight at $4^{\circ} \mathrm{C}$ in a 1:200 dilution of the caspase- 9 antibody, a 1:1000 dilution of the Apaf-1 antibody or a 1:2000 dilution of the cytochrome $c$ antibody. Sections were then washed three times in PBS and incubated for $1 \mathrm{~h}$ at room temperature in a 1:1000 dilution of goat anti-rabbit Сy3 or goat anti-mouse FITC (fluorescein isothiocyanate) immunoconjugate (Jackson Immunoresearch, West Grove, PA, USA). Sections were then washed and mounted in medium containing 4',6 diamidino-2-phenylindole (DAPI Vector Laboratories, Burlingame, CA, USA) to assess nuclear morphology. Cell phenotype was determined by staining with mouse monoclonal anti-NeuN (Chemicon, Temecula, CA, USA) and FITC- or AMCA-conjugated goat anti-mouse secondary antibody (Jackson Immunoresearch). In additional sections the primary antibody was omitted to assess non-specific staining. Immunolabeling was studied using a Leica microscope equipped for epifluorescent illumination under excitation/emission wavelengths of $340 / 425 \mathrm{~nm}$ (blue), $500 /$ $550 \mathrm{~nm}$ (green) and 580/630 nm (red). Images were collected using an Optronics DEI-750 3-chip camera equipped with a BQ 8000 sVGA frame grabber and analyzed using an image analysis system (Bioquant, Nashville, TN, USA).

Analysis of cells exhibiting DNA fragmentation was performed using a fluorescein-based terminal deoxynucleotidyl transferase (TdT)-mediated dUTP nick end labeling (TUNEL) technique (Roche Molecular Biochemicals, Indianapolis, IN, USA) to label doublestranded DNA breaks suggestive of apoptosis. Following fixing and permeabilization, sections were incubated with the TUNEL reaction mixture (Roche Molecular Biochemicals) and then processed as described for immunohistochemistry.

\section{Intracerebroventricular administration of z-LEHD-fmk}

Studies were performed as previously described with modifications. ${ }^{25,27}$ Animals were implanted with a cannula (coordinates from
Bregma; $A P=-0.8 \mathrm{~mm} ; \mathrm{L}=-1.4 \mathrm{~mm}$ ) to allow i.c.v. infusion (Harvard pump) of $0.2 \mu \mathrm{g} z$-LEHD-fmk (Enzyme Systems Products, Livermore, CA, USA) in $2 \mu \mathrm{l}$ volume at a rate of $1 \mu \mathrm{l} / \mathrm{min}$. Drug vehicle was $0.5 \%$ dimethylsulfoxide (DMSO) in artificial cerebrospinal fluid (Harvard Apparatus). Infusions were performed $30 \mathrm{~min}$ and $5 \mathrm{~min}$ before KA administration and $1 \mathrm{~h}$ after KA for enzyme assays. Caspase-9-like (LEHDase), caspase-3/7-like (DEVDase) and caspase-2-like (VDVADase) activity was measured according to the methods described above and previously. ${ }^{25,27}$ Animals euthanized for histology received a fourth z-LEHD-fmk infusion (cumulative dose $0.8 \mu \mathrm{g}$ ) $24 \mathrm{~h}$ after KA to ensure maintenance of z-LEHD-fmk levels according to previously established protocols by our group and our collaborators. ${ }^{25,27}$ Controls included animals that received intraamygdala saline and i.c.v. vehicle (non-seizure controls) and intraamygdala KA and i.c.v. vehicle (seizure controls). Animals were euthanized $4 \mathrm{~h}$ after diazepam for enzyme assay or after $72 \mathrm{~h}$ for TUNEL positive cell counts and histopathology (surviving cell counts on cresyl violetstained sections). Cell counts along the entire hippocampal CA3 pyramidal layer were performed in duplicate on adjacent sections at the level of Bregma $-2.5 \mathrm{~mm}$ according to anatomical locations defined in a rat brain atlas. ${ }^{64}$ Cell counts in cresyl violet-stained sections were performed blinded to treatment. Surviving neurons exhibiting normal morphology within the anatomically defined field of interest were included in counts while shrunken and grossly irregular shaped neurons were omitted. TUNEL-positive cells were counted using scanning software (Bioquant).

\section{Data analysis}

Data are presented as mean \pm standard error of the mean (S.E.M.). Data were analyzed using one-way analysis of variance (ANOVA) with appropriate post hoc tests (StatView software, SAS Institute, Inc., Cary, NC, USA). Significance was accepted at $P<0.05$.

\section{Acknowledgements}

This research was supported by R01 NS39016 (DC Henshall and RP Simon). Many thanks to Sue Crawford for secretarial support.

\section{References}

1. Savitz SI and Rosenbaum DM (1998) Apoptosis in neurological disease. Neurosurgery 42: $555-572$

2. Thornberry NA and Lazebnik Y (1998) Caspases: enemies within. Science 281: $1312-1316$

3. Schulz JB, Weller M and Moskowitz MA (1999) Caspases as treatment targets in stroke and neurodegenerative diseases. Ann. Neurol. 45: 421-429

4. Duan H, Orth K, Chinnaiyan AM, Poirier GG, Froelich CJ, He WW and Dixit VM (1996) ICE-LAP6, a novel member of the ICE/Ced-3 gene family, is activated by the cytotoxic T cell protease granzyme B. J. Biol. Chem. 271: 16720-16724

5. Kuida K, Haydar TF, Kuan CY, Gu Y, Taya C, Karasuyama H, Su MS, Rakic P and Flavell RA (1998) Reduced apoptosis and cytochrome c-mediated caspase activation in mice lacking caspase 9. Cell 94: 325-337

6. Krajewski S, Krajewski M, Ellerby LM, Welsh K, Xie Z, Deveraux QL, Salvesen GS, Bredesen DE, Rosenthal RE, Fiskum G and Reed JC (1999) Release of caspase-9 from mitochondria during neuronal apoptosis and cerebral ischemia. Proc. Natl. Acad. Sci. USA 96: 5752-5757

7. Zhivotovsky B, Samali A, Gahm A and Orrenius S (1999) Caspases: their intracellular localization and translocation during apoptosis. Cell Death Differ. 6: $644-651$

8. Zou H, Henzel WJ, Liu X, Lutschg A and Wang X (1997) Apaf-1, a human protein homologous to $c$. elegans CED-4, participates in cytochrome $c$-dependent activation of caspase-3. Cell 90: 405-413 
9. Li P, Nijhawan D, Budihardjo I, Srinivasula SM, Ahmad M, Alnemri ES and Wang X (1997) Cytochrome $c$ and dATP-dependent formation of Apaf-1/caspase- 9 complex initiates an apoptotic protease cascade. Cell 91: 479-489

10. Zhou P, Chou J, Olea RS, Yuan J and Wagner G (1999) Solution structure of Apaf-1 CARD and its interaction with caspase-9 CARD: a structural basis for specific adaptor/caspase interaction. Proc. Natl. Acad. Sci. USA 96: 1126511270

11. Cain K, Bratton SB, Langlais C, Walker G, Brown DG, Sun XM and Cohen GM (2000) Apaf-1 oligomerizes into biologically active approximately $700-\mathrm{kDa}$ and inactive approximately 1.4-MDa apoptosome complexes. J. Biol. Chem. 275: 6067-6070

12. Hu Y, Benedict MA, Ding L and Nunez G (1999) Role of cytochrome $c$ and dATP/ ATP hydrolysis in Apaf-1-mediated caspase-9 activation and apoptosis. EMBO J. $18: 3586-3595$

13. Day CL, Dupont C, Lackmann M, Vaux DL and Hinds MG (1999) Solution structure and mutagenesis of the caspase recruitment domain (CARD) from Apaf-1. Cell Death Differ. 6: 1125-1132

14. Rodriguez $\mathrm{J}$ and Lazebnik $Y$ (1999) Caspase-9 and APAF-1 form an active holoenzyme. Genes Dev. 13: 3179-3184

15. Hakem R, Hakem A, Duncan GS, Henderson JT, Woo M, Soengas MS, Elia A, de la Pompa JL, Kagi D, Khoo W, Potter J, Yoshida R, Kaufman SA, Lowe SW, Penninger JM and Mak TW (1998) Differential requirement for caspase 9 in apoptotic pathways in vivo. Cell 94: 339-352

16. Cecconi F (1999) Apaf1 and the apoptotic machinery. Cell Death Differ. 6:10871098

17. Yoshida H, Kong YY, Yoshida R, Elia AJ, Hakem A, Hakem R, Penninger JM and Mak TW (1998) Apaf1 is required for mitochondrial pathways of apoptosis and brain development. Cell 94: 739-750

18. Pollard H, Charriaut-Marlangue C, Cantagrel S, Represa A, Robain O, Moreau J and Ben-Ari Y (1994) Kainate-induced apoptotic cell death in hippocampa neurons. Neuroscience 63: 7-18

19. Sloviter RS, Dean E, Sollas AL and Goodman JH (1996) Apoptosis and necrosis induced in different hippocampal neuron populations by repetitive perforant path stimulation in the rat. J. Comp. Neurol. 366: 516-533

20. Fujikawa DG, Shinmei SS and Cai B (2000) Kainic acid-induced seizures produce necrotic, not apoptotic, neurons with internucleosomal DNA cleavage: implications for programmed cell death mechanisms. Neuroscience 98: 41-53

21. Fujikawa DG, Shinmei SS and Cai B (2000) Seizure-induced neuronal necrosis: implications for programmed cell death mechanisms. Epilepsia 41: S9-S13

22. Gillardon F, Bottiger B, Schmitz B, Zimmermann M and Hossmann K-A (1997) Activation of CPP32 protease in hippocampal neurons following ischemia and epilepsy. Mol. Brain Res. 50: 16-22

23. Faherty CJ, Xanthoudakis S and Smeyne RJ (1999) Caspase-3-dependent neuronal death in the hippocampus following kainic acid treatment. Mol. Brain Res. 70: $159-163$

24. Ferrer I, Lopez E, Blanco R, Rivera R, Krupinski J and Marti E (2000) Differential c-Fos and caspase expression following kainic acid excitotoxicity. Acta Neuropathol. (Berl) 99: 245-256

25. Henshall DC, Chen J and Simon RP (2000) Involvement of caspase-3-like protease in the mechanism of cell death following focally evoked limbic seizures. J. Neurochem. 74: 1215-1223

26. Henshall DC, Clark RS, Adelson PD, Chen M, Watkins SC and Simon RP (2000) Alterations in bcl-2 and caspase gene family protein expression in human temporal lobe epilepsy. Neurology 55: 250-257

27. Henshall DC, Skradski SL, Bonislawski DP, Lan JQ and Simon RP (2001) Caspase-2 activation is redundant during seizure-induced neuronal death. J. Neurochem. 77: 886-895

28. Griffiths T, Evans MC and Meldrum BS (1983) Intracellular calcium accumulation in rat hippocampus during seizures induced by bicuculline or L-allylglycine. Neuroscience 10: 385-395

29. Griffiths T, Evans MC and Meldrum BS (1984) Status epilepticus: the reversibility of calcium loading and acute neuronal pathological changes in the rat hippocampus. Neuroscience 12: 557-567

30. Henshall DC, Sinclair J and Simon RP (2000) Spatio-temporal profile of DNA fragmentation and its relationship to patterns of epileptiform activity following focally evoked limbic seizures. Brain Res. 858: 290-302

31. Ben-Ari Y, Tremblay E and Ottersen OP (1980) Injections of kainic acid into the amygdaloid complex of the rat: an electrographic, clinical and histological study in relation to the pathology of epilepsy. Neuroscience 5: 515-528
32. Henshall DC, Sinclair JS and Simon RP (1999) Relationship between seizureinduced transcription of the DNA damage-inducible gene GADD45, DNA fragmentation and neuronal death in focally evoked limbic epilepsy. J. Neurochem. 73: 1573-1583

33. Meldrum BS (1986) Cell damage in epilepsy and the role of calcium in cytotoxicity. Adv. Neurol. 44: 849-855

34. Lu DC, Rabizadeh S, Chandra S, Shayya RF, Ellerby LM, Ye X, Salvesen GS, Koo EH and Bredesen DE (2000) A second cytotoxic proteolytic peptide derived from amyloid beta-protein precursor. Nat. Med. 6: 397-404

35. Thornberry NA, Rano TA, Peterson EP, Rasper DM, Timkey T, Garcia-Calvo M, Houtzager VM, Nordstrom PA, Roy S, Vaillancourt JP, Chapman KT and Nicholson DW (1997) A combinatorial approach defines specificities of members of the caspase family and granzyme B. Functional relationships established for key mediators of apoptosis. J. Biol. Chem. 272: 17907-17911

36. Ashkenazi A and Dixit VM (1998) Death receptors: signaling and modulation. Science 281: 1305-1308

37. Ashkenazi A and Dixit VM (1999) Apoptosis control by death and decoy receptors. Curr. Opin. Cell Biol. 11: 255-260

38. Green DR and Reed JC (1998) Mitochondria and apoptosis. Science 281: $1309-1312$

39. Ouyang YB, Tan Y, Comb M, Liu CL, Martone ME, Siesjo BK and Hu BR (1999) Survival- and death-promoting events after transient cerebral ischemia: phosphorylation of Akt, release of cytochrome $\mathrm{C}$ and activation of caspaselike proteases. J. Cereb. Blood Flow Metab. 19: 1126-1135

40. Fujimura M, Morita-Fujimura Y, Noshita N, Sugawara T, Kawase M and Chan PH (2000) The cytosolic antioxidant copper/zinc-superoxide dismutase prevents the early release of mitochondrial cytochrome $c$ in ischemic brain after transient focal cerebral ischemia in mice. J. Neurosci. 20: 2817-2824

41. Yang JC and Cortopassi GA (1998) Induction of the mitochondrial permeability transition causes release of the apoptogenic factor cytochrome $c$. Free Radic. Biol. Med. 24:624-631

42. Szalai G, Krishnamurthy R and Hajnoczky G (1999) Apoptosis driven by IP(3)linked mitochondrial calcium signals. EMBO J. 18: 6349-6361

43. Shimizu S and Tsujimoto $Y(2000)$ Proapoptotic BH3-only Bcl-2 family members induce cytochrome $c$ release, but not mitochondrial membrane potential loss, and do not directly modulate voltage-dependent anion channel activity. Proc. Natl. Acad. Sci. USA 97: 577-582

44. Meldrum BS (1994) The role of glutamate in epilepsy and other CNS disorders. Neurology 44: S14-S23

45. Chen D, Stetler RA, Cao G, Pei W, O'Horo C, Yin XM and Chen J (2000) Characterization of the rat DNA fragmentation factor $35 /$ Inhibitor of caspaseactivated DNase (Short form). J. Biol. Chem. 275: 38508-38517

46. Hausmann G, O'Reilly LA, van Driel R, Beaumont JG, Strasser A, Adams JM and Huang DC (2000) Pro-apoptotic apoptosis protease-activating factor 1 (Apaf-1) has a cytoplasmic localization distinct from Bcl-2 or Bcl-x(L). J. Cell Biol. 149: $623-634$

47. Bratton SB, Walker G, Srinivasula SM, Sun XM, Butterworth M, Alnemri ES and Cohen GM (2001) Recruitment, activation and retention of caspases- 9 and -3 by Apaf-1 apoptosome and associated XIAP complexes. EMBO J. 20: 998-1009

48. Chen F, Hersh BM, Conradt B, Zhou Z, Riemer D, Gruenbaum Y and Horvitz HR (2000) Translocation of C. elegans CED-4 to nuclear membranes during programmed cell death. Science 287: 1485-1489

49. Von Ahsen O, Waterhouse NJ, Kuwana T, Newmeyer DD and Green DR (2000) The 'harmless' release of cytochrome $c$. Cell Death Differ. 7: 1192-1199

50. Zheng TS, Hunot S, Kuida K, Momoi T, Srinivasan A, Nicholson DW, Lazebnik Y and Flavell RA (2000) Deficiency in caspase-9 or caspase-3 induces compensatory caspase activation. Nat. Med. 6: 1241-1247

51. Inohara N, Koseki T, del Peso L, Hu Y, Yee C, Chen S, Carrio R, Merino J, Liu D, Ni $J$ and Nunez G (1999) Nod1, an Apaf-1-like activator of caspase-9 and nuclear factor-kappaB. J. Biol. Chem. 274: 14560-14567

52. Sperandio S, de Belle I and Bredesen DE (2000) An alternative, nonapoptotic form of programmed cell death. Proc. Natl. Acad. Sci. USA 97: 14376-14381

53. Martin-Villalba A, Herr I, Jeremias I, Hahne M, Brandt R, Vogel J, Schenkel J, Herdegen T and Debatin KM (1999) CD95 ligand (Fas-L/APO-1L) and tumor necrosis factor-related apoptosis- inducing ligand mediate ischemia-induced apoptosis in neurons. J. Neurosci. 19: 3809-3817 
54. Velier JJ, Ellison JA, Kikly KK, Spera PA, Barone FC and Feuerstein GZ (1999) Caspase- 8 and caspase- 3 are expressed by different populations of cortical neurons undergoing delayed cell death after focal stroke in the rat. J. Neurosci. 19: $5932-5941$

55. Kondratyev A and Gale K (2000) Intracerebral injection of caspase-3 inhibitor prevents neuronal apoptosis after kainic acid-evoked status epilepticus. Mol. Brain Res. 75: 216-224

56. Samali A, Zhivotovsky B, Jones D, Nagata S and Orrenius S (1999) Apoptosis: cell death defined by caspase activation. Cell Death Differ. 6: 495-496

57. Vaux DL (1999) Caspases and apoptosis - biology and terminology. Cell Death Differ. 6: $493-494$

58. Kitanaka C and Kuchino Y (1999) Caspase-independent programmed cell death with necrotic morphology. Cell Death Diff. 6: 508-515

59. Fujikawa DG, Itabashi HH, Wu A and Shinmei SS (2000) Status epilepticusinduced neuronal loss in humans without systemic complications or epilepsy. Epilepsia 41: $981-991$
60. Aminoff MJ (1998) Do nonconvulsive seizures damage the brain? -No. Arch Neurol. 55: 119-120

61. Young GB and Jordan KG (1998) Do nonconvulsive seizures damage the brain?-Yes. Arch. Neurol. 55: 117-119

62. Kalviainen R, Salmenpera T, Partanen K, Vainio P, Riekkinen P and Pitkanen A (1998) Recurrent seizures may cause hippocampal damage in temporal lobe epilepsy. Neurology 50: 1377-1382

63. Tasch E, Cendes F, Li LM, Dubeau F, Andermann F and Arnold DL (1999) Neuroimaging evidence of progressive neuronal loss and dysfunction in temporal lobe epilepsy. Ann. Neurol. 45: 568-576

64. Paxinos $P$ and Watson $C$. The rat brain in stereotaxic coordinates. third ed. San Diego: Academic Press, Inc.; 1997. 